\title{
WET CHEMICAL SYNTHESIS, CHARACTERIZATION, AND ANTIBACTERIAL ACTIVITY OF MOLYBDENUM OXIDE NANOPARTICLES AGAINST STAPHYLOCOCCUS EPIDERMIDIS AND ENTEROBACTER AEROGENES
}

\author{
POONAM SANGWAN ${ }^{1 *}$, HARISH KUMAR ${ }^{2}$, RENU RANI ${ }^{3}$
}

${ }^{1}$ Department of Chemistry, GC Hisar, Haryana, India. ${ }^{2}$ Department of Chemistry, Central University of Mahendergarh, Haryana, India. ${ }^{3}$ Department of Quality and Identity, Singh Plasticisers and Resin (I) Manufacturers Pvt., Ltd., Bhiwadi, Raj., India.

Email: poonam.sangwan35@gmail.com

Received: 5 November 2018, Revised and Accepted: 08 February 2019

ABSTRACT

Objective: The objective of this study was to synthesize the molybdenum oxide nanoparticles (NPs) by employing wet chemical method and investigation of their antibacterial properties against pathogenic bacteria.

Methods: Molybdenum trioxide $\left(\mathrm{MoO}_{3}\right) \mathrm{NPs}$ were synthesized using an eco-friendly wet chemical sol-gel technique. The synthesized MoO ${ }_{3} \mathrm{NPs}$ were characterized using X-ray diffraction (XRD), transmission electron microscopy (TEM), Fourier-transform infrared spectroscopy, and ultravioletvisible spectroscopic techniques to confirm the obtained product, size shape, morphology, functional groups, and absorption spectra, respectively. The size of the $\mathrm{MoO}_{3} \mathrm{NPs}$ was found to be $41 \mathrm{~nm}$. The antibacterial activity of these metal NPs was investigated on Staphylococcus epidermidis and Enterobacter aerogenes by measuring the zone of inhibition and colony-forming units on solid medium and by measuring the optical density of the culture solution. Antibacterial activity of $\mathrm{MoO}_{3} \mathrm{NPs}$ was also compared with well-known standard antibiotics.

Results: The antibacterial activities of molybdenum oxide NPs possessing size $41 \mathrm{~nm}$ were compared with standard antibiotics such as oxacillin, cotrimoxazole, erythromycin, clindamycin, chloramphenicol, and tetracycline. It was found that all of these antibiotics were effective against Staphylococcus epidermidis while Enterobacter aerogenes was resistant to oxacillin, co-trimoxazole and clindamycin, whereas the $\mathrm{MoO}_{3}$ nanoparticles were found to be effective against both of these bacterial pathogens.

Conclusion: Inorganic antimicrobial agents have advantages over organic antimicrobial agents due to their stability, preparation methods, and their ability to prevent bacteria to develop multidrug resistant. It was observed that $\mathrm{MoO}_{3}$ nanoparticles (NPs) possess good antibacterial properties; therefore, these can be used in pharmaceutical industries and provide a path for further research regarding the toxicity study for its use in human being.

Keywords: X-ray diffraction, Transmission electron microscopy, Staphylococcus epidermidis, Enterobacter aerogenes, antibacterial activity.

(c) 2019 The Authors. Published by Innovare Academic Sciences Pvt Ltd. This is an open access article under the CC BY license (http://creativecommons. org/licenses/by/4. 0/) DOI: http://dx.doi.org/10.22159/ajpcr.2019.v12i4.30644

\section{INTRODUCTION}

In recent years due to eruption of infectious diseases caused by different pathogenic bacteria and the development of antibioticresistant species due to the repeated use of the antibiotics, the researchers are searching for new antibacterial agents. The number of organic substances shows the antibacterial activity, but most of them are toxic in nature. Therefore, the ultimate target of nanoscience and nanotechnology is to present opportunities for exploring the bactericidal effect of metal oxide NPs due to their high stability and nontoxic nature [1]. NPs, especially metallic ones, tend to offer an effective solution for overcoming bacterial resistance [2-7]. The transition metal oxides are attracting a great deal of attention in the field of material science due to its variety of crystal phases and properties. Among the transition metal oxide, molybdenum trioxide $\left(\mathrm{MoO}_{3}\right)$ exhibits better intercalation chemistry with unique chemical, electrochemical, electronic, and catalytic properties. $\mathrm{MoO}_{3}$ is renowned model compound for selective oxidation catalysis [8,9], photocatalysis [10], electrochromism [11], lithium-ion batteries [12], light-emitting diodes, etc. [13] $\mathrm{MoO}_{3}$ shows polymorphism and can be synthesized in different morphologies such as nanorods [14], nanobelts [15], and nanowires [16] for various applications. The nanomaterials, based on the metal ions, exhibit broad-spectrum biocidal activity toward diverse bacteria, fungi, and viruses [17]. Zollfrank et al. [18] reported that antimicrobial activity of transition metal acid $\mathrm{MoO}_{3}$ is related to their surface acidity involving the intermediate formation of molybdic acid. The modification of various materials (e.g., polymers and metals) with $\mathrm{MoO}_{3}$ particles showed that the modified material surfaces were practically free of microorganisms $6 \mathrm{~h}$ after contamination with infectious agents. Krishnamoorthy et al. [19] studied the toxicity of $\mathrm{MoO}_{3}$ toward pathogenic bacteria. According to this report, the prepared $\mathrm{MoO}_{3}$ nanoplates exhibit good antibacterial activity against four tested bacterial species Escherichia coli, Salmonella typhimurium, Bacillus subtilis, and Enterococcus faecalis. Ruben et al. reported that $\mathrm{MoO}_{3} \mathrm{NPs}$ act as potential therapeutic for sulfite oxidase deficiency [20]. Neha et al. [21] reported the synthesis of nanocrystalline h-MoO ${ }_{3}$ through chemical bath deposition technique studies on its phase transition and investigated the antibacterial properties of $\mathrm{h}-\mathrm{MoO}_{3}$ and $\alpha-\mathrm{MoO}_{3}$ against Gram-positive Bacillus megaterium and Streptococcus aureus and Gram-negative E. coli.

\section{METHODS}

\section{Reagents and test organisms}

Staphylococcus epidermidis (Microbial Type Culture Collection [MTCC] 3382) and Enterobacter aerogenes (MTCC 2823) were obtained from MTCC, Institute of Microbial Technology, Chandigarh. All other chemicals used in experiment were of analytical grade and from standard chemical sources.

\section{Synthesis of $\mathrm{MoO}_{3} \mathrm{NPs}$}

In the present study, the $\mathrm{MoO}_{3} \mathrm{NPs}$ were synthesized using environmentfriendly sol-gel technique [22]. The $\mathrm{MoO}_{3}$ solution was prepared by dissolving it in double distilled water, and in another beaker, oxalic acid solution was prepared. The $\mathrm{MoO}_{3}$ solution was then stirred for $1 \mathrm{~h}$, 


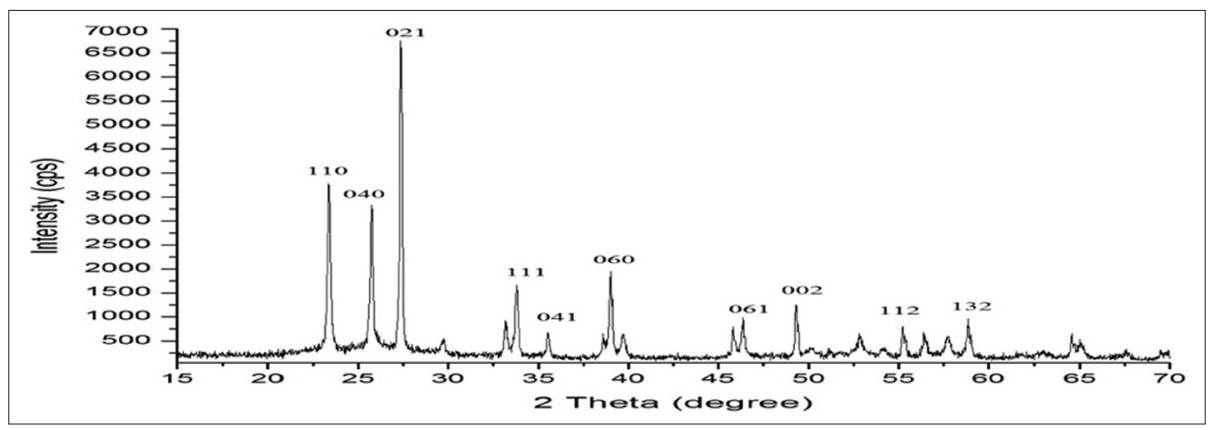

Fig. 1: X-ray diffraction pattern of molybdenum oxide nanoparticles

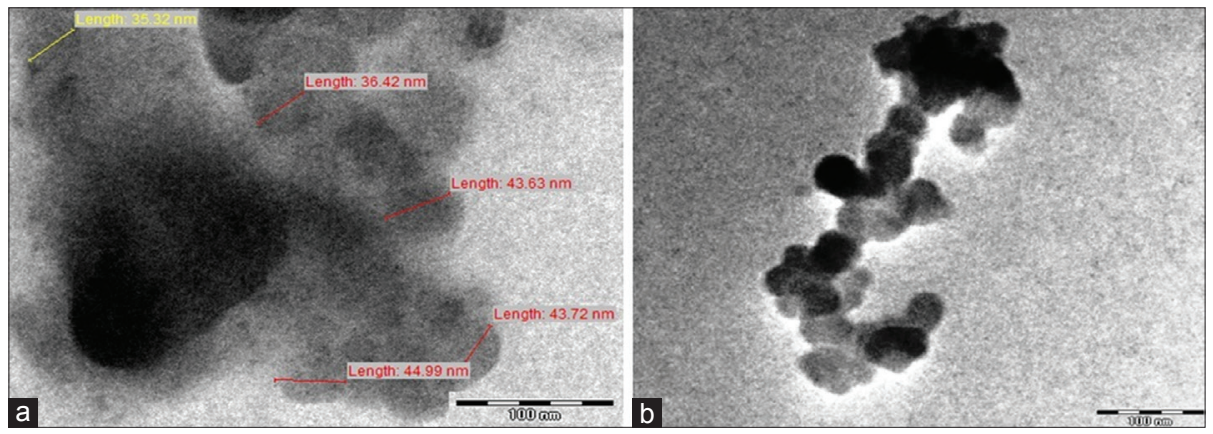

Fig. 2: ( $a$ and b) Transmission electron microscopy images of molybdenum oxide nanoparticles

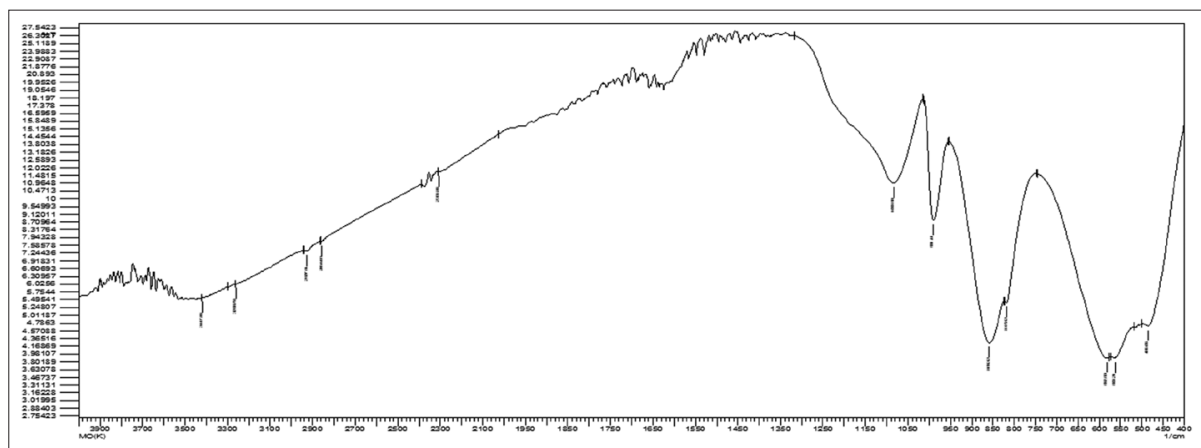

Fig. 3: Fourier transform infrared spectra of molybdenum oxide nanoparticles

and simultaneously, the oxalic acid solution was stirred for $1 / 2 \mathrm{~h}$. The oxalic acid solution was then mixed in $\mathrm{MoO}_{3}$ solution dropwise with continuous stirring for $3.0 \mathrm{~h}$. The resultant solution was then filtered and washed with double distilled water several times. The resulting gelatinous precipitates were then heated at $100^{\circ} \mathrm{C}$ into an oven for $5.0 \mathrm{~h}$, and finally, the precipitates were put in a muffle furnace at $500^{\circ} \mathrm{C}$ for $2.0 \mathrm{~h}$.

\section{Characterization techniques}

The size, structure, and morphology of as-prepared metal NPs were

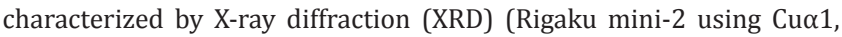
$\lambda=0.15406 \mathrm{~nm}$ radiations), transmission electron microscopy (TEM) (FEI-Philips, Morgagni 286D with magnification up to $\times 280,000$, Acc. Voltage: $100 \mathrm{Kv}$ ), Fourier-transform infrared spectroscopy (FTIR) (Shimadzu Corp-02014) in the wavelength range of 400-4000 $\mathrm{cm}^{-1}$, and ultraviolet (UV)-visible spectroscopy (Shimadzu 1800) in the wavelength range of $200-1000 \mathrm{~cm}^{-1}$.

\section{Antibacterial study}

Antibacterial activity of the $\mathrm{MoO}_{3}$ NPs against a Gram-positive [23] $S$. epidermidis and a Gram-negative E. aerogenes bacterial pathogens was investigated by measuring zone of inhibition (ZOI), colony-forming unit (CFU), and optical density (OD). Antibacterial activity of $\mathrm{MoO}_{3} \mathrm{NPs}$ was also compared with standard antibiotics. The zone of inhibition was measured in mm by agar well diffusion method. The bacterial

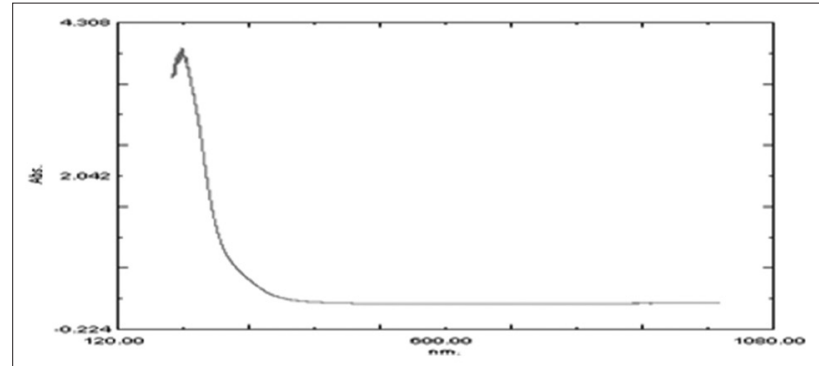

Fig. 4: Ultraviolet-visible spectra of molybdenum oxide nanoparticles

Table 1: MIC of molybdenum oxide and titanium dioxide metal NPs against $S$. epidermidis and E. aerogenes

\begin{tabular}{lll}
\hline Sr. No. & Bacteria & MIC in $\mathbf{m g} / \mathbf{m l}$ \\
\cline { 3 - 3 } & & $\begin{array}{l}\text { Molybdenum oxide } \\
\text { nanoparticles }\end{array}$ \\
\hline 1 & S. epidermidis & 30.0 \\
2 & E. aerogenes & 30.0 \\
\hline
\end{tabular}

E. aerogenes: Enterobacter aerogenes, MIC: Minimum inhibition concentration,

S. epidermidis: Staphylococcus epidermidis, NPs: Nanoparticles 


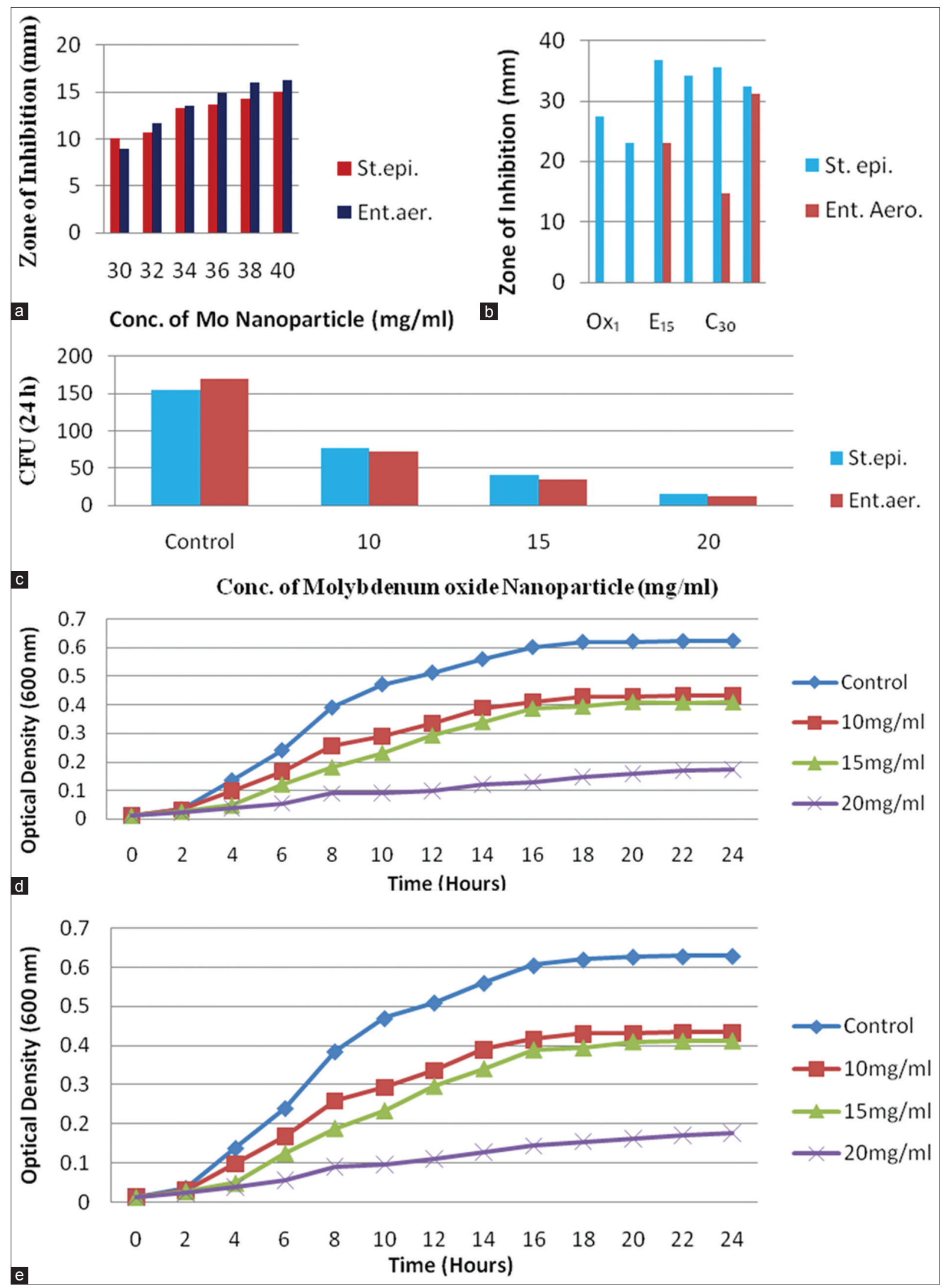

Fig. 5: (a) Zone of inhibition for Mo oxide nanoparticle (NP), (b) zone inhibition with different antibiotics, (c) colony-forming unit characterization of molybdenum oxide NPs against Staphylococcus epidermidis and Enterobacter aerogenes, (d) effect of molybdenum oxide NPS on the growth of S. epidermidis, (e) effect of molybdenum oxide NPS on the growth of E. aerogenes

spread onto the solidified agar plates. The wells were prepared in the agar medium with the help of a cork borer. These wells were then 
loaded with different concentrations of $\mathrm{MoO}_{3} \mathrm{NPs}$ suspension in double distilled water. The CFU of the bacterial culture was evaluated with different concentrations $(10,15$, and $20 \mathrm{mg} / \mathrm{ml})$ of $\mathrm{MoO}_{3}$ NPs using the standard broth dilution method. The growth behavior of $S$. epidermidis and $E$. aerogenes was investigated by measuring the OD through the administration of different concentrations of $\mathrm{MoO}_{3} \mathrm{NPs}$ into the dilute solution of the broth.

\section{RESULTS AND DISCUSSION}

\section{Characterization of molybdenum oxide NPs}

Fig. 1 shows XRD pattern of the chemically synthesized molybdenum oxide NPs. The XRD pattern revealed major peaks at $2 \mathrm{q}$ values of 23.36 (110), 25.74 (040), 27.36 (021), 33.78 (111), 35.52 (041), 39.02 (060), 46.34 (061), 49.3 (002), 55.24 (112), 58.84 (132), and 64.56 , respectively $[24,25]$. The experimental XRD pattern agrees with the JCPDS card no. 35-0609, $a=3.9630 \AA, b=13.8560 \AA$, and $c=3.6966$ $\AA$. The XRD peaks correspond to the orthorhombic crystal structure of $\mathrm{MoO}_{3}$. The XRD analysis of the sample synthesized by the sol-gel technique confirms the formation of $\alpha-\mathrm{MoO}_{3} \mathrm{NPs}$. Average particle size of the molybdenum oxide NPs corresponding to the highest intensity peak was found to be $41.0 \mathrm{~nm}$ using Scherrer's formula $(\mathrm{d}=\mathrm{K} \lambda / \beta \cos \theta)$.

Fig. 2 shows the TEM images of molybdenum oxide nanoparticles. The particles were observed to be almost spherical. It can be seen from Fig. 2 that there is a uniform distribution of particle with mean particle size $40.81 \mathrm{~nm}$ which is in close agreement with the XRD result.

Figure 3 shows the FTIR spectra of molybdenum oxide nanoparticles. Broadband at 582 and $563 \mathrm{~cm}^{-1}$ is may be due to $0-\mathrm{Mo}-0$ bending. The band at 991and $1083 \mathrm{~cm}^{-1}$ is due to $M o=0$ stretching and two bands at 858 and $817 \mathrm{~cm}^{-1}$ came from Mo-0-Mo stretching. These bands almost correspond to $\alpha-\mathrm{MoO}_{3}$ data [25]. A band at 3417 is due to $\mathrm{O}-\mathrm{H}$ stretching vibration of adsorbed water molecule on the surface of $\mathrm{MoO}_{3}$ nanoparticles.

Fig. 4 shows the ultraviolet (UV)-visible spectra of molybdenum oxide nanoparticles (NPs) synthesized by sol-gel method. The absorption maxima observed at $212.2 \mathrm{~nm}$, which falls under the UV-C region. The UV-C region is called the short wave UV region which ranges from 200 to $280 \mathrm{~nm}$. Hence, this indicates that $\mathrm{MoO}_{3} \mathrm{NPs}$ absorb the UV rays effectively. The band energy gap was found to be about $5.84 \mathrm{eV}$.

\section{Antibacterial activity of molybdenum oxide nanoparticles}

Fig. 5 (a) shows the ZOI produced by different concentrations $(30,32,34,36$, 38 , and $40 \mathrm{mg} / \mathrm{ml}$ ) of the $\mathrm{MoO}_{3} \mathrm{NPs}$ against $S$. epidermidis and E. aerogenes. It was found that the ZOI increases with increase in the concentration of the $\mathrm{MoO}_{3}$ NPs. Fig. 5 (b) shows the ZOI produced by standard antibiotics such as oxacillin, cotrimoxazole, erythromycin, clindamycin, chloramphenicol, and tetracycline. It was found that all of these antibiotics were effective against Staphylococcus epidermidis while Enterobacter aerogenes was resistant to oxacillin, co-trimoxazole and clindamycin, whereas the $\mathrm{MoO}_{3}$ nanoparticles were found to be effective against both of these bacterial pathogens. Fig. 5 (c) shows the $\mathrm{CFU} / \mathrm{ml}$ of the dilute bacterial broth supplemented with different concentrations $(0,10,15$, and $20 \mathrm{mg} / \mathrm{ml})$ of $\mathrm{MoO}_{3} \mathrm{NPs}$. It was found that the $\mathrm{CFU}$ has been reduced significantly with increase in the conc. Of the $\mathrm{MoO}_{3}$ NPs. Fig. 5 (d) and (e) shows the timedependent changes in the bacterial growth monitored at a regular interval of $2 \mathrm{~h}$ (up to $24 \mathrm{~h}$ ) by measuring OD of the control and bacterial solutions supplemented with different concentrations $(10,15$, and $20 \mathrm{mg} / \mathrm{ml})$ of $\mathrm{MoO}_{3} \mathrm{NPs}$. It is clear that slope of the bacterial growth curve is continuously decreased with increasing concentration of the NPs. Table 1 shows the minimum inhibitory concentration (MIC) of the $\mathrm{MoO}_{3}$ NPs against both of the investigated bacterial strains.

\section{CONCLUSION}

In this study, molybdenum oxide NPs of mean size $41 \mathrm{~nm}$ were synthesized using eco-friendly, rapid, and inexpensive sol-gel technique. Antibacterial activity of these $\mathrm{MoO}_{3}$ NPs against a Gram- positive S. epidermidis and Gram-negative Enterobacter aerogenes bacterial pathogens was investigated by measuring ZOI, CFU, and OD. Antibacterial activity of $\mathrm{MoO}_{3}$ NPs was also compared with standard antibiotics. The MIC of these NPs was found to be $30 \mathrm{mg} / \mathrm{ml}$ for both of the investigated bacteria. The CFUs decrease with increase in the conc. of the metal NPs. The results obtained from the ZOI, CFU, and OD measurements were in close agreement with each other. IIt was found that all of these antibiotics were effective against Staphylococcus epidermidis while Enterobacter aerogenes was resistant to oxacillin, co-trimoxazole and clindamycin, whereas the $\mathrm{MoO}_{3}$ nanoparticles were found to be effective against both of these bacterial pathogen. This study shows that $\mathrm{MoO}_{3} \mathrm{NPs}$ hold good antibacterial properties; consequently, these can be used in pharmaceutical industries and provide a path for further research regarding the toxicity study for its use in human being.

\section{ACKNOWLEDGMENT}

The authors gratefully acknowledge the support of the University Grant Commission of India for this research work.

\section{AUTHORS' CONTRIBUTIONS}

Poonam Sangwan was involved the synthesis, characterization, and antibacterial study of molybdenum oxide NPs.

Harish Kumar guided this research at each and every step.

Renu Rani helps in antibacterial study.

\section{CONFLICTS OF INTEREST}

The authors declare that they have no conflicts of interest.

\section{REFERENCES}

1. Hajipour MJ, Fromm KM, Ashkarran AA, Jimenez de Aberasturi D, de Larramendi IR, Rojo T, et al. Antibacterial properties of nanoparticles. Trends Biotechnol 2012;30:499-511.

2. Shinde MD, Chavan PG, Umarji GG, Arbuj SS, Rane SB, More MA, et al. Field emission and photo-catalytic investigations on hierarchical nanostructures of copper doped cdS synthesized by kitchen-chemistry approach. J Nanosci Nanotechnol 2012;12:3788-98

3. Shinde M, Patil R, Karmakar S, Bhoraskar S, Rane S, Gade W, et al. Antimicrobial properties of uncapped silver nanoparticles synthesized by DC arc thermal plasma technique. J Nanosci Nanotechnol 2012;12:887-93.

4. Sangwan P, Kumar H, Purewal SS. Antibacterial activity of chemically synthesized chromium oxide nanoparticles against Enterococcus faecalis. Int J Adv Technol Eng Sci 2016;4:550-7.

5. Sangwan P, Kumar H. Synthesis characterization and antibacterial activities of chromium oxide nanoparticles against Klebsiella pneumoniae. Asian J Pharm Clin Res 2017;10:1-4

6. Murugesan S, Bhuvaneswari S, Sivamurugan V. Green synthesis, characterization of silver nanoparticles of a marine red alga Spyridia fusiformis and their antibacterial activity. Int J Pharm Pharm Sci 2017;9:192-7.

7. Selvarani M. Investigation of the synergistic antibacterial action of copper nanoparticles on certain antibiotics against human pathogens. Int J Pharm Pharm Sci 2018;10:83-6.

8. Grasselli RK. Fundamental principles of selective heterogeneous oxidation catalysis. Top Catal 2002;21:79-88.

9. Arumugam M, Gang JL, Chin YC, Jing HC, Shih HM, Tzzy LH, et al. Synthesis of $\mathrm{MoO} 3$ nanoparticles for azo dye degradation by catalytic ozonation. Mater Res Bull 2015;62:184-91.

10. Huang L, Xu H, Zhang R, Cheng X, Xia J, Xu Y, et al. Synthesis, characterization of g-C3N4-MoO3 photocatalyst with improved photocatalytic activity. Appl Surf Sci 2013;283:25-32

11. Yao DD, Field MR, O'Mullane AP, Kalantar-Zadeh K, $\mathrm{Ou}$ JZ. Electrochromic properties of $\mathrm{TiO} 2$ nanotubes coated with electrodeposited MoO3. Nanoscale 2013;5:10353-9.

12. Sen UK, Mitra S. Electrochemical activity of $\alpha-\mathrm{MoO} 3$ nanobelts as lithium ion battery cathode. RSC Adv 2012;2:11123-31.

13. Fu Q, Chen J, Shi C, Ma D. Room-temperature sol-gel derived molybdenum oxide thin films for efficient and stable solution-processed organic light-emitting diodes. ACS Appl Mater Interfaces 2013;5: $6024-9$ 
14. Zhang L, Xu Y, Jin D, Xie Y. Well aligned molybdenum oxide nanorods on metal substrate: Solution based synthesis and their electrochemical capacitor application. J Mater Chem 2010;20:7135-43.

15. Zhou L, Yang L, Yuan P, Zou J, Wu Y. $\alpha$-MoO3 nanobelts: A high performance cathode material for lithium ion batteries. J Phys Chem C 2010;114:21868-72.

16. Liang R, Cao H, Qian D. MoO3 nanowires as electrochemical pseudocapacitor materials. Chem Commun (Camb) 2011;47:10305-7.

17. Baker C, Pradhan A, Pakstis L, Pochan DJ, Shah SI. Synthesis and antibacterial properties of silver nanoparticles. J Nanosci Nanotechnol 2005;5:244-9

18. Zollfrank C, Gutbrod K, Wechsler P, Guggenbichler JP. Antimicrobial activity of transition metal acid $\mathrm{moO}(3)$ prevents microbial growth on material surfaces. Mater Sci Eng C Mater Biol Appl 2012;32:47-54.

19. Krishnamoorthy K, Veerapandian M, Yun K, Kim SJ. New function of molybdenum trioxide nanoplates: Toxicity towards pathogenic bacteria through membrane stress. Colloids Surf B Biointerfaces 2013; $112: 521-4$
20. Ruben R, Filipe N, Muhammad NT, Henning J, Anubha K, Dennis S, et al. Molybdenum trioxide nanoparticleswith intrinsic sulfite oxidase activity. Am Chem Soc 2014;8:5182-9.

21. Neha D, Sawanta M, Vijay K, Rahul M, Chang H, Popatrao B. Chemically grown $\mathrm{MoO} 3$ nanorods for antibacterial activity study. J Nanomed Nanotechnol 2015;6:1-7.

22. Kumar H, Sangwan P, Luthra M. Synthesis and characterization of cobalt oxide nanoparticles by sol-gel method. Adv Appl Phys Chem Sci A Sustain Approach 2014;21:99-104.

23. Dighore N, Jadhav S, Anandgaonker P, Gaikwad S, Rajbhoj A. Molybdenum oxide nanoparticles as antimicrobial agents. J Cluster Sci 2017:28:109-18.

24. Song JM, Zhao SJ, Hu Y, Ren MS, Shi YL, Ni XM. Self-assembly orthorhombic and hexagonal MoO3 microrods and their application in catalytic dyes decoloration. J Anhui Univ 2013;37:7-14.

25. Kanneganti A, Manasa C, Doddapaneni P. A sustainable approach towards synthesis of $\mathrm{MoO} 3$ nanoparticles using Citrus limetta pith extract. Int J Eng Adv Technol 2014;3:128-30. 